\title{
Museus e Exposição das Catástrofes: Políticas
}

\section{Museums and Exhibition of Disasters: Policies}

\author{
Giulia Crippa*
}

* Recebido em: 15.02.2017. Aprovado em: 20.07.2017

**Livre-docente em Ciências da Informação pela USP, professora da Informação pela USP, professora da
USP - Ribeirão Preto, e também do Programa de Pós-Graduação em Ciência da Informação da ECA/USP Doutora em História Social pela USP. Email: giuliac@ffclrp.usp.br
Resumo: o artigo discorre acerca das maneiras pelas quais museus e memoriais lidam com o sentido de "catástrofe", como os museus de Hiroshima, de Minamoto e Auschwitz/Birkenau, discutindo a representação social de fatos históricos e da memória. Essa questão é problematizada pela discussão das modalidades de transformação dos lugares de memória em função do fenômeno do turismo de massa, complementada por ponderações sobre as representações do fim das instituições cuja função é representar a memória, principalmente museus.

Palavras-Chave: Museus. Memória. Catástrofes. Turismo.
Abstract: the article discusses the ways in which museums and memorials deal with the meaning of "catastrophe", such as the Hiroshima, Minamoto and Auschwitz / Birkenau museums, discussing the social representation of historical facts and memory. This question is problematized by the discussion of the modalities of transformation of places of memory according to the phenomenon of mass tourism, complemented by considerations about the representations of the end of institutions whose function is to represent memory, especially museums.

Keywords: Museums. Memory. Catastrophes. Tourism. 


\section{Introdução}

Que o pensamento reflita sobre o fim individual ou coletivo, dotado dos elementos que desenham uma ideia de Apocalipse, ou que se confronte com o paradigma empírico da catástrofe na história, o que se observa são representações contraditórias do trauma.

Filosoficamente, a representação do fim se torna mito no diálogo platônico sobre as últimas horas de Sócrates, durante as quais o medo do filósofo é o apagamento do logos quando se depara com o fim, uma condição na qual a catástrofe é a da linguagem, encalhada na falta de sentido da existência perante a morte. O que, porém, garante o naufrágio do pensamento, a catástrofe da linguagem, é a hipótese do fim do tempo. O que permite enfrentar esse abismo é o mito, como relato possível da Imaginação, que se torna tempo narrativo, relato de tempo infinito, mas ainda assim, de tempo, e não do fim, que é sua ausência inconcebível.

O fim, então, somente se apreende por narrativas que, em geral, remetem a concepções escatológicas, lineares, fundamentando-se em ideias de um fim de natureza moral. A razão, porém, só pode observar e aceitar a transformação dos fenômenos em outros fenômenos, ou pelo menos é essa a esfera da experiência. Como já comentava Lucrecio no III livro do De Rerum Natura, nós podemos olhar para o fim, para a morte, somente como sobreviventes, porque é a única maneira de poder narrar, imaginar.
Por definição, a única testemunha possível é a do fim alheio.

Procuraremos discutir, assim, como museus e memoriais lidam com o sentido de "catástrofe", como o museu de Hiroshima e o de Minamoto, analisados por Jeudy (2005). Falaremos de como o Museu de Auschwitz/Birkenau tem removido o memorial dos deportados italianos por ser "muito artístico" e, principalmente, por carregar símbolos controversos, provocando uma "catástrofe" da memória do próprio museu.

Encerra nosso texto um esboço analítico do Museu de Arte Otsuka, no Japão: o museu adquire sentido somente na perspectiva de uma catástrofe, do fim, e tece sua narrativa pela trama da tecnologia. O Museu de Otsuka existe porque a empresa Otsuka desenvolve uma tecnologia que, entre outras coisas, permite garantir uma espécie de eternidade a uma certa memória da arte.

\section{Catástrofe e memórias}

Vivemos em uma época em que a palavra museu precisa ser declinada no plural. É também uma época em que precisa aceitar que uma das principais razões de visita aos museus é representada pela inclusão dos mesmos em pacotes turísticos. Obviamente, a dimensão do turismo de massa transforma nossa relação com lugares que já tiveram papel de consagração da arte, da história, da ciência e da tecnologia. Podemos pensar que todo museu é um conjunto de documentos de natureza física e conceitual diferente, organizados em arranjos que buscam validar o presente. Os 
Museus, sistematicamente, foram e são utilizados como instrumentos de comunicação de princípios e valores por parte de seus stakeholders.

Seguindo esse raciocínio, tentamos individualizar de que maneira as instituições de memória têm elaborado suas narrativas do "fim", de que maneira propuseram a elaboração das "catástrofes". Temos consciência de que é necessário oferecer um conjunto de referências que permitam entender melhor o sentido de catástrofe escatológica, que está na base das instituições de memória que iremos analisar. Remetemos, por isso, a Davis (2002), que discute os medos apocalípticos da vida urbana americana, em que as cidades se tornam o emblema do combate contra as catástrofes provocadas por elementos naturais, mas também de lugares que se tornaram representativos de catástrofes tecnológicas. Particularmente interessante, no nosso contexto, é o capítulo dedicado ao Museu do Tsunami no Havaí. É uma área geologicamente instável, onde dois tsunamis (1946 e 1960) provocaram tragédias, lembradas por uma praça memorial, um aterro na altura da onda mais alta do último tsunami e o Museu do Tsunami do Pacífico, inaugurado em 1996. Davis esclarece de maneira eficaz as mudanças nas "propostas" de memória cultural provocadas pelo turismo. Observa as estratégias de elaboração e representação da memória do trauma afirmando que:

Até mesmo um visitante casual ao museu, abrigado num enorme prédio art-déco [...] que suportou as fúrias de 1946 e 1960, acab fascinado com as narrativas homéricas dos sobreviventes que vêm "contar historias" e visitar amigos. [...] No entanto, o terreno da memória é complexo, e o museu é obviamente uma coalizão de diferentes agendas. [...] Pelo menos quatro tipos de interesse participam da atual memorização dos tsunamis como "herança da ilha." (DAVIS, 2002, p. 134).

Em seguida, identifica esses interesses em "desenvolvimentistas", que "percebem a história dos tsunamis como um empolgante tema-aventura para atrair mais dólares dos turistas ricos" (DAVIS, 2002, p. 135), "viúvas herdeiras", preocupadas em preservar a hegemonia das famílias tradicionais, "aficionados" dos tsunamis, pessoas fascinadas pelo "romance desses cataclismos espetaculares" e "ativistas", que tentam preservar as tradições locais contra o fenômeno do turismo globalizado. É um exemplo poroso da relação entre imaginários ligados às tradições culturais ocidentais, autóctones e importadas pelos imigrantes japoneses. Isso permitiu ver - em um contexto em que o autor lida pelo foco das Ciências Ambientais das mudanças urbanas, nesse caso ligadas ao turismo - como os vários agentes discursivos que representam os envolvidos afetam a ideia de catástrofe natural que, por sua vez, é representada.

Muitos são os autores que buscaram nortear definições e representações das catástrofes propriamente humanitárias, dentre os quais destacamos Huyssen (2014), que traça uma interessante panorâmica das últimas décadas em relação ao desenvolvimento de políticas e instituições memoriais, além de Zevi, (2014), que nos 
conduz através das inúmeras obras memoriais e de arte que designam e desenham - freqüentemente através de "antimonumentos" - o holocausto.

Jeudy (2005) estuda algumas narrativas das "memórias" de catástrofes da humanidade, evidenciando os recursos desenvolvidos pelos atores institucionais para elaborar uma narrativa da catástrofe na sua musealização. Lugares de memória, em que o sofrimento adquire caráter exemplar, em que os registros são feitos com o sangue, têm um valor destacado: são inesquecíveis na medida em que são traduzidos em recordações que vinculam positivamente um grupo

Observa Jeudy que

Da precária tumba erguida na beira da estrada até o memorial, a lógica patrimonial permanece idêntica: o acidente, a catástrofe e a guerra estão representados pelos símbolos que asseguram a rememoração (JEUDY, 2005, p. $58)$.

Essa rememoração exerce um papel de coesão social e na sua base se encontra a catástrofe, acontecimento sem dúvida "aglutinador" de solidariedades e, nesse sentido, com grandes potencialidades memoriais. Porém, reforçando as premissas de nossa introdução, Jeudy afirma que "o que é negado pelo mecanismo da comemoração é a degradação do sentido engendrado pelo desastre. O que permanece como não dito é a memória da morte absurda" (2005, p. 59)

É preciso, porém, esclarecer, para entender as próximas considerações, que lugares traumáticos se diferenciam de lugares memorativos na medida em que os primeiros se fecham a uma formação afirmativa de sentido. "Memórias oficiais têm sangue e vítimas, mas a lembrança não é traumática pela conotação normativa para a fixação de sentido individual ou coletivo." (ASSMAN, 2011, p. 349)

Exemplo disso é o Museu da Paz de Hiroshima, dedicado a lançar a mensagem "nunca mais" ao uso da bomba atômica. O museu, visitado por turistas e crianças, escolheu uma narrativa em que a representação dos efeitos da explosão atômica são encadeados à ideia de catástrofe. Consequência dessa escolha de apresentação é que "a transmissão da mensagem proposta, mesmo que fundada na situação de guerra, orienta [...] o olhar do visitante na direção da constatação trágica de uma fatalidade do destino" (JEUDY, 2005, p. 60). O que torna eficaz o museu são alguns elementos materiais, em que a ausência, o indizível, o fim se materializam como testemunhas da catástrofe: como no pedestal de mármore sobre o qual é traçada, com o giz, a silhueta de um corpo incinerado pela explosão ou os vestidos que sobreviveram aos corpos na explosão. A presença dos objetos e a ausência dos corpos impedem que o museu de Hiroshima se torne

uma abstração formal [...]. Quando desaparecem, como no museu de Nagasaki, o tratamento das memórias de guerra torna-se comparável às estratégias contemporâneas de "guerra cirúrgica": o que se apagou foi o próprio cadáver. (JEUDY, 2005, p. 65) 
Jeudy ainda trata do museu das "falhas geológicas" em Kobe, individualizando escolhas narrativas que seguem uma lógica didática e sem recursos artísticos no percurso de exibição:

o visitante é convidado primeiro a se dar conta dos efeitos da irrupção do desastre na vida cotidiana, recebendo em seguida uma boa lição didática que lhe dá as informações científicas necessárias para compreender o que se passou e que pode acontecer novamente. (JEUDY, 2005, p. 62

Por último, trata de dois museus de Minamata, dedicados à catástrofe humana e ambiental provocada pelas altas dosagens de mercúrio nos peixes; um dos quais abriga, além do museu, um arquivo e um centro de pesquisa. Nessa instituição,

o tratamento e a apresentação científica $[\ldots]$ permitem que o público compreenda o que aconteceu, ao mesmo tempo impondo uma reflexão didática sobre o drama propriamente dito. (JEUDY, 2005, p. 63)

O segundo museu dispõe de recursos fotográficos e de objetos que evocam o presente da tragédia. $\mathrm{O}$ que o autor aqui sugere não é uma escolha entre as duas narrativas expositivas, mas sim, uma reflexão sobre as alternativas e complementaridades possíveis na organização dos materiais e das narrativas da catástrofe dos eventos traumáticos.

O que aparenta estar em pauta, aqui, não é a natureza das imagens que testemunham as catástrofes, mas a ênfase dada a determinadas narrativas pelos elementos que elas evocam, assim como os objetos que compõem as narrativas.
Ajuda a entender esse conceito um ensaio de DidiHuberman (2007), que, ao confrontar a linguagem de uma foto de reportagem premiada de Jorge Merillion com uma obra de arte a ela inspirada de Pascal Convert, ambas caracterizadas pela representação da morte e da dor, mostra como a catástrofe individual é, através do prêmio, elevada a símbolo do trauma e como essa catástrofe é colonizada por linguagens: a documentação de Merillon do velório, a partir de sua premiação, passa a ser conhecida como A piedade do Kossovo (DIDI-HUBERMAN, 2007).

Trata-se de uma fotografia cuja legenda original era: “ Nagafc, 29 de janvier 1990. Veillée funèbre au Kosovo autor do corps de Nasimi Elshani, tué lors d'une manifestation pour l'indépendance du Kosovo". Como afirma Sontag (2004),

uma foto não é apenas uma imagem (como uma pintura é uma imagem), uma interpretação do real; é também um vestígio, algo diretamente decalcado do real, como uma pegada ou uma máscara mortuária. (SONTAG, 2004, p. 170)

O que acontece com a foto de Merillon é que a dor passa a ser categorizada pelas características da representação em primeiro lugar pictórica da iconografia ocidental. Algo parecido aconteceu com uma fotografia de Hocine Zaourar, em 1997, que documenta a guerra civil na Algéria e uma extraordinária fotografia sua passa a ser conhecida como A Madona de Bentalha.

Essa linguagem se torna perigosa por várias razões: 
1) Enfatizando o laço estético com os lugares comuns da pintura, privilegia a compaixão em detrimento da informação, ou seja: um estado afetivo (pathos/passivo) em oposição a uma questão política (ethos/ação). Reforçando unicamente sua proximidade com tradições estéticas, as fotos se tornam monumentos, deixando em segundo plano, excessivamente desfocada, sua função de documentos.

2) $\mathrm{Na}$ tentativa de obter empatia imediata, no lugar da compreensão paciente ligada a uma memória histórica, gesto para o qual necessitamos de uma reconstituição de fatos, a fotografia é apresentada como apelo à memória visual de algo que conhecemos, em um processo de esquecimento do dado histórico documental - estetização monumento, que se caracteriza pela sua compreensão imediata.

3) O uso de referências cristãs, como "Piedade" ou "Madona", afasta e dificulta a própria compreensão dos fatos, acontecidos, em ambos os casos, em países muçulmanos. Opera-se uma verdadeira colonização dos sentidos em uma "grade semântica" em que os valores e modelos são cristãos.

Diferente é a relação que se estabelece com a obra de arte de Convert, imagem de memória ativa dentro da linguagem escolhida, a ser interpretada, por sua natureza, pela lógica monumental.
Foram Aby Warburg (DIDI HUBERMAN, 2013, MICHAUD, 1998) e Walter Benjamin (1987) os primeiros a se perguntarem, já na primeira metade do século XX, qual é o destino de uma imagem. Destino, para eles, é aquilo que a história, como forma específica de memória, gera para além de si mesma, aquilo que a vincula àquele passado que escolheu esquecer, silenciar. Aquilo que não contou, do qual, portanto, não tem memória. A memória, construída na temporalidade da história, é informativa, e as imagens tornam visíveis aquilo que a história gera para além de si, adquirem um destino. A historicidade, em ambos os casos, devemos sublinhar, se constrói conforme memória e desejos que a sustentam em um nível subconsciente. O ofício dessa "construção", desse conhecimento, porém, é percorrido por um determinado pensamento, por determinadas práticas de "montagem", e Warburg, em 1927, elabora o projeto de um Atlas de imagens, que denomina Mnemosyne. Mnemosyne é a musa da memória, e Clio é uma de suas filhas, a musa da história, e não é tarefa dela ilustrar o Atlas. Uma "página" do Atlas é dedicada à dor extrema na iconografia. Warburg recolhe as representações ocidentais de pathos desde a Grécia até as fotografias de seu tempo, e o faz de maneira antropológica. A "página" seguinte ilustra a iconografia do luto e da pietas. (DIDI-HUBERMAN, 2013)

Depois da II Guerra se observa a insurgência de um novo lugar comum universal, representado pelo Holocausto e pelo seu poder memorativo. Aby Warburg, que morreu em 1929, 
1 Trata-se de uma das organizações antifascista de matriz liberal e não comunista que participaram do Comitê de Libertação Nacional. No caso da resistência italiana, intelectuais como Beppe Fenoglio, Leone Ginzburg, Giulio Einaudi entre outros, foram antifascistas liberais. obviamente não tinha esse lugar comum no seu atlas, mas o Holocausto abriu uma página inédita na representação do fim e do apocalipse. Mas, como todos os lugares comuns, as "declinações" da representação da catástrofe seguem vontades e desejos dos stakeholders, os quais não somente dão diretrizes para construir a narrativa na base de determinadas seleções de materiais. Eles decidem também em que medida é melhor um museu no modelo de Hiroshima ou mais "limpo" como Nagasaki; se é desejável um Museu com um grande centro de pesquisa ou o pequeno museu que apela diretamente à memória através dos objetos e das imagens, como em Minamoto. Para Assman (2011), enquanto o local da catástrofe se estabiliza por meio da história que se conta sobre ele e que mesmo sustenta e torna verídica - uma testemunha que acompanha a narrativa -, o local traumático marca a memória indizível pela razão, o fim: "O lugar traumático preserva a virulência de um acontecimento que permanece, como um passado que não se esvai, que não logra guardar distância." (ASSMAN, 2011, p. 350).

Exemplar, nesse sentido, é o Memorial representado pelo campo de concentração e de extermínio de Auschwitz/Birkenau, na Polônia, e a diatribe que envolveu o Memorial italiano, obra encomendada pela Associação Nacional dos ex-deportados ao arquiteto Lodovico Barbiano de Belgiojoso (ativo, entre 1933 e 1936, com Pietro Maria Bardi entre outros, na revista Quadrante). $\mathrm{O}$ arquiteto Belgiojoso, de família nobre, inscrito ao partido fascista, foi extremamente ativo nos fóruns de discussão sobre o modernismo arquitetônico da época. Em 1936, ano em que foram promulgadas as leis raciais na Itália, o arquiteto Belgiojoso recusou-se a renovar sua inscrição ao partido fascista e aproximouse do movimento antifascista Giustizia e Libertál. Belgiojoso, capturado em 1944, foi deportado como prisioneiro político para o campo de concentração de Mathausen, de onde foi libertado pelas tropas aliadas.

O Memorial foi inaugurado em 1980 no bloco 21 do exdormitório do campo de extermínio de Auschwitz. Entre seus idealizadores está o escritor Primo Levi, autor das palavras escritas para o visitante, que inspiraram a própria obra (www.deportati.it/lager/alvisitatore.html).

A questão é que, desde 2008, a obra foi fechada pela direção do Museu de Auschwitz/Birkenau, que a considerou destoante das outras instalações, dispositivos de natureza mais didática e documentária. A obra do bloco 21, que tinha como finalidade "impedir que a obra dos assassinos coincida exatamente com o memorial de suas vítimas, como em Auschwitz, onde foi culpadamente desmantelado [...] o belíssimo memorial italiano em espiral [...]" (ZEVI, A. 2014, p. 161), merece ser ilustrada para entender que a escolha narrativa da linguagem artística foi a representação considerada adequada pelos ex-deportados, que vivenciaram aquela catástrofe que precisava se tornar memória.

Depois de ler as palavras de Primo Levi, o visitante 
2 Ricorda cosa ti hanno fatto in Auschwitz, para vozes e fita magnética, composição de Luigi Nono (https://www.youtube.com/watch?v=z-IUbwaMC0) caminhava por oitenta metros ao longo de uma passarela moldada como trilhos de trem, dentro de um "túnel" de tecido, interrompido por aberturas que deixavam ver os outros blocos do lager. No interior do túnel acompanhando a trajetória entre as imagens pintadas no túnel, tocava a trilha sonora dessa descida ao Inferno ${ }^{2}$. A obra, pioneira da linguagem multimedial, devia trazer à consciência o pesadelo dos deportados, dividido entre a angústia de uma morte quase certa e a tênue esperança da sobrevivência. As imagens se dispõem para contar o caminho que levou à catástrofe: símbolos e rostos ilustram a tomada de poder pelo fascismo, as lutas operárias, a guerra civil espanhola, os tratados com Hitler, as leis raciais, a entrada em guerra, a luta antifascista, as deportações raciais e políticas, a libertação por parte dos aliados, até a abertura final.

Nesse ambiente estão presentes poucas escritas e muitas sugestões originadas pelo desejo dos idealizadores de explicar a experiência das deportações como foram vividas por um país aliado aos alemães. É por isso que a instalação não se concentra na experiência do lager, mas sobre as razões da catástrofe, enraizada na própria concepção fascista. Voltamos a repetir que a instalação foi realizada por ex-deportados de origem política antifascista, sem distinção entre matrizes liberais ou comunistas: é preciso sublinhar esse caráter da instalação para compreender que na arquitetura da catástrofe (representada pelos campos de extermínio e, em seguida, pelo Memorial e Museu de Auschwitz/Birkenau) havia atores diversos daqueles de um filme do bem que derrota o mal. O Memorial italiano carregava símbolos que remetiam ao comunismo, em um lugar da memória situado na Polônia, onde o comunismo foi posto fora da lei e onde, em 1991, na cidade de Poznan "é inaugurado um museu dedicado ao anticomunismo, baseado na documentação da luta contra o comunismo." (VERCELLONI, V., 2007, p. 260).

O rosto de Gramsci, a foice e martelo, o Exército Vermelho (que literalmente, abriu os portões do campo em 1945) se tornaram símbolos indesejáveis para o museu que se propõe a representar a catástrofe do século XX. O fato de o comunismo ter desempenhado um papel determinante entre os grandes antagonistas dos fascismos tornou-se irrelevante. A exclusão dessa instalação se torna negação da memória da deportação, na medida em que os campos de concentração se alimentaram de presos políticos comunistas. De um ponto de vista propriamente museológico, o pecado é ainda mais grave e joga uma luz perigosa sobre a representação das catástrofes: a decisão de fechar a instalação porque pouco didática ou por ferir os sentimentos anticomunistas leva a não atribuir à própria instalação um papel na história das concepções memoriais do lugar desde sua fundação. Assim como no museu de Nagasaki desapareceu o "corpo do delito", em Auschwitz se observa um princípio de "seleção" entre as vítimas, negando a parte delas o direito a serem lembradas. Escolhas de narrativa, escolha de linguagens, uso político da memória agregada à representação do 
fim/apocalipse.

\section{A solução ao apocalipse}

Silva (2014) estuda o uso das imagens de algumas catástrofes por parte da mídia - os terremoto do Haiti (2010), do Chile (2010) e do Japão (2011), esse último acompanhado por tsunamis - e aponta para uma clara manipulação das imagens que se fundamenta em estereótipos que facilitam a visualização e o entendimento dos acontecimento. Portanto, a representação da tragédia no Haiti foi dominada por imagens de cadáveres empilhados, de desamparo e de abandono, a representação de "um povo pobre, faminto e arrasado por um desastre natural" (SILVA, 2014, p. 80), sem as condições mínimas para enfrentá-lo. Na representação do terremoto chileno, dominam imagens de prédios destruídos, panorâmicas de ruas e cidades, destacando a reação ativa das vítimas. Em ambos os casos, a reação foi de reconhecimento do drama e compaixão (no sentido acima apontado) pelas vítimas desses lugares.

O terceiro caso, a catástrofe do Japão, se tornou um relato ao vivo do apocalipse, conforme surgiam imagens, vídeos e se disseminavam notícias sobre possíveis riscos nucleares. Medo da Natureza e medo do progresso incontrolável tornaram uma catástrofe Japonesa ícone global do fim.

Um lugar capaz de resistir a uma catástrofe como essa já existia no Japão: é o Museu de Arte Otsuka, inaugurado em 1998 para comemorar os setenta e cinco anos do ramo farmacêutico da corporação Otsuka. Trata-se de um museu pensado com base em uma tecnologia "antídoto" contra o fim, capaz de preservar memórias, através da reprodução de altíssima qualidade de centenas de obras de arte, selecionadas dentro do conjunto dos cânones da arte ocidental. O museu é instalado em uma edificação construída segundo normas extremamente rigorosas para garantir a segurança do conteúdo em caso de catástrofes naturais ou provocadas pelos homens, pois esse "santuário" da arte não deve ruir, nem por um terremoto, nem por um tsunami, nem por uma explosão atômica. O museu de arte de Otsuka é um exemplo extraordinário da possibilidade de regenerar historicamente toda a cultura artística ocidental: vasos gregos, mosaicos romanos, afrescos pompeianos e medievais, pinturas desde a Idade Media até a contemporaneidade são reproduzidos em cerâmica, através de sofisticadas tecnologias que garantem qualidade altíssima nos detalhes e nas cores. Até uma réplica em tamanho original da Capela Sistina é presente, ainda que somente nas partes realizadas por Michelangelo, enquanto as paredes da capela original, realizadas por outros artistas em momentos diferentes não foram reproduzidas, pois o comitê não as incluiu entre as obras primas.

O que isso representa? Por que uma realização desse porte não pode ser descartada como algo de pouca conta, como algo que leva ao sorriso? Esse espaço dedicado à possibilidade tecnológica de reprodução não somente infinita, como igual ou superior ao 
original, se propõe a representar o antídoto ideal e necessário contra a catástrofe do esquecimento. No lugar de serem rejeitados, os aspectos seriais e mecânicos da cultura industrial passaram a ser valorizados como sinais do espírito que troca a antiguidade e a autenticidade pela novidade e pela quantidade que é, na verdade, uma questão ideológica presente no museu. A Otsuka é uma corporação que se ocupa de produtos químicos e farmacêuticos: a história é narrada em forma de storytelling pelo neto do fundador da empresa, com sábias referências aos ancestrais, isso é, à tradição e à inovação. No centro, está uma dessas operações de inovações, quando um dos funcionários, rico em espírito corporativo, sugere tentar a produção de cerâmicas de alta qualidade com areia local. É o início de uma fase de experimentação destinada a levar à produção de cerâmicas com reproduções de obras de artistas japoneses. Aos poucos, os painéis de até um metro quadrado de cerâmica industrial foram produzidos com os principais ícones da arte ocidental, destinadas a sobreviverem a seus próprios originais. É um lugar onde as potencialidades humanas de sobreviver se manifestam amplificadas na arquitetura, nas reproduções e na seleção "universal" das obras. Se considere, por exemplo, se pode ser relevante uma parede de cerâmicas cuidadosamente tratadas para representarem a Ultima ceia de Leonardo, em tamanho natural que pode ser vista por centenas de pessoas por dia sem ser danificada. Impensável, nos sugere o mesmo senso comum que norteou a escolha das obras. Porém o museu está aberto e recebe milhares de visitantes por ano, um bunker de segurança máxima que garante que se nós não sobrevivermos, não será o fim. Uma visão decididamente utópica, de fácil entendimento e de gratificante representação de um futuro em que algo de nós sobrevive. Não se tratam de memórias futuras originais, mas algo que desponta como memória do futuro. Quem salva a memória universal é a tecnologia produzida pela Otsuka, que, nesse storytelling (empresarial e museológico ao mesmo tempo), é capaz, muito mais que qualquer museu anterior, de superar o fim, a Catástrofe. Nessa espécie de imensa arca de Noé da cultura ocidental, a sensibilidade de nosso olhar tornou-se para sempre puro produto de nossa inteligibilidade.

Como definir esse lugar, museu do fake? O primeiro problema, perante esse lugar, é constituído pela sua própria denominação: é um museu de arte, ou pelo menos é assim que se define na página principal do site, enquanto a especificidade dessa arte se encontra somente após uma mais escrupulosa visão das páginas web a ele dedicadas.

O site assim descreve o museu:

Com um espaço de 29.412 metros quadrados, esse
museu de obras primas reproduzidas em placas de
cerâmicas é o maior espaço expositivo do Japão,
com uma coleção de mais de 1.000 reproduções de
obras primas da arte ocidental (http://o-
museum.or.jp/english/publics/index/16/)

Um comitê de seis historiadores da arte de renome 
em 25 países. A seleção foi realizada com a devida consideração do desenvolvimento histórico da arte Ocidental entre a Antiguidade e o século XX. O que o museu pretende é "transmitir a aparência real da imagem para um período ilimitado de tempo, com a finalidade de preservá-la it como herança para as futures gerações." ( http://omuseum.or.jp/english/publics/index/18/ )

Em outra página do site, encontra-se a explicação da técnica de reprodução e a referência explícita à empresa capaz de tamanha realização: através de uma técnica de trabalho cerâmico altamente refinada, a companhia de cerâmicas Otsuka Ohmi conseguiu reproduzir as obras selecionadas no tamanho idêntico às originais (http://o-museum.or.jp/english/publics/index/17/).

Diferentemente de ver essas obras primas reproduzidas em escala reduzida em livros de arte ou cartões postais, as reproduções em tamanho original exibidas pelo Museu Otsuka de Arte oferece aos visitantes a oportunidade de apreciar reproduções artísticas mais próximas dos originais. A proposta "oficial" desse local inédito é de conhecer imagens de alguns entre os maiores museus do mundo e, como é dito no site: um dia, tendo a oportunidade, as pessoas que visitaram o Museu de Otsuka podem viajar para o Ocidente e, encontrando os originais, lembrar da experiência vivida no museu das cópias. E mesmo que não viagem, eles tiveram a oportunidade de conhecer Uma inversão notável das referências para a memória!

\section{Considerações finais}

Parece-nos que caibam, a essa altura, algumas ponderações sobre as representações do fim das instituições cuja função é representar a memória, principalmente museus. Em primeiro lugar, temos consciência da necessidade de aprofundar a modalidade de transformação dos lugares de memória em função do fenômeno do turismo de massa. Essa temática, a ser desenvolvidas em outros momentos, tem seus pensadores, entre os quais elegemos Augè (2003, 2009 e 2010), que consideramos ponto de partida para a abordagem desse tópico.

Os museus, pela definição do ICOM, consensualmente adotada por muitos países (http://icom.museum/thevision/museum-definition/), são instituições abertas ao público, engajadas com o patrimônio da humanidade desde sua coleção até sua comunicação, passando pela pesquisa e a preservação. No entanto, as escolhas dos objetos e das imagens, a escolha de seus arranjos dentro de um espaço que já, em si, "significa", por ser parte dos acontecimentos memoriais ou por ter sido construído exnovo para hospedar as memórias se fundamentam em princípios que presidem essa ordem.

Museus e memoriais existem, supostamente, para impedir o fim. Todo museu e memorial fala do fim como algo que pode ser “adiado", evitado, exatamente porque o museu e/ou o memorial existem para impedir o fim. Quando o lugar de memória é explicitamente dedicado aos traumas provocados por catástrofes, 
ou seja, quando o lugar de memória busca explicitar o discurso que se aniquila, que não mais existe, realiza uma operação que responde aos interesses (às vezes contrapostos) dos próprios stakeholders desse lugar.

Temos, assim, as diversas perspectivas de investimento dos vários stekeholders do Museu do Tsunami, dedicado a uma catástrofe natural, mas que deve narrá-la como aventura, como heróica intervenção das famílias locais, como fenômeno espetacular da natureza e como lugar de preservação das tradições contra o turismo de massa. Com tudo isso, aparentemente, não há muito espaço para a reflexão sobre o fim, finalidade última do museu, ainda mais quando ele é dedicado a representar o trauma da catástrofe, onde houve destruição e morte.

Nos museus de Hiroshima e de Nagasaki, cuja função é monumental, pois é a de "admoestar", alertar sobre a catástrofe, relatando o trauma da explosão atômica, as políticas expositivas e narrativas são controversas. Em Hiroshima, a presença de determinados objetos, os quais remetem ao lugar "sem palavras", bem como em Minamoto, no menor dos dois museus, a memória do fim transparece, enquanto em Nagasaki e no museu e centro turístico e de pesquisa Minamoto a catástrofe tornou-se asséptica. Os dois museus dedicados à catástrofe provocada pelo envenenamento por mercúrio não somente contam com linguagens diferentes, mas recebem investimentos bem distintos, e é possível ver qual narrativa e linguagem é privilegiada.
A mesma narrativa passou a ser privilegiada em Auschwitz/Birkenau: a lógica, o discurso racional e didático buscam erradicar o próprio fim, eliminar a catástrofe do indizível, com efeitos paradoxais. No verão de 2015, pelas altas temperaturas que dificultavam as visitas turísticas, a direção do memorial de Auschwitz encontrou uma solução: instalou umas fileiras de chuveiros com os quais os visitantes podiam se refrescar. Uma escolha macabra, para um lugar destinado a lembrar de como se aplicou cientificamente um extermínio. Nesse mesmo lugar, o memorial do Bloco 21, isso é, algo elaborado utilizando linguagens que decorrem dos debates estéticos e artísticos, é considerado uma linguagem não idônea. É nesse sentido que Didi-Huberman se tornou um dos autores chave para uma discussão sobre as linguagens que encenam a memória, pois permite reconhecer o uso de documentos como monumentos e de monumentos como documentos sem que a linguagem que investe a "intenção" (de documento o de objeto artístico) seja colocada em pauta.

Ambas as linguagens convivem na representação do fim, pois ambas permitem a recuperação da memória. O que se observa é a construção, muitas vezes, de uma falsa oposição entre as duas linguagens e a exclusão da linguagem e do arranjo artístico como menos válidos para essas representações. O fim, porém, pede também contemplação, palavras míticas, representações que encenem a catástrofe do discurso, sua inaptidão para com fim, seu limite, o vácuo de sua ausência. Também se trata de discurso, que 
trata de seus limites e não mais de sua onipotência. Isso porque, do outro lado, o triunfo de políticas que tendem a destacar a habilidade humana em limitar, cercear, "derrotar" as catástrofes, seja pela ciência, seja pelos imperativos repetidos e retóricos do "nunca mais" revelam princípios de negação da própria catástrofe. A ciência provocou algum desastre? Sabendo como foi, "nunca mais" se repetirá. O homem foi capaz de criar o horror do campo de extermínio? Vamos conhecer tudo, até a fórmula do Zyclon B, para que "nunca mais" isso aconteça. Enquanto o turista, com direito a todos os confortos, se refresca em um dos chuveiros instalados para que a visita se torne mais agradável.

Tudo isso encontra seu apogeu no Museu de Otsuka, em que a afirmação estrutural é que catástrofe nenhuma poderá destruir esse lugar. A catástrofe, sempre presente, é derrotada definitivamente pelo engenho humano, que na reprodução das mercadorias, finalmente se eterniza. Se estes forem os princípios que norteiam a memória em tempos de globalização, é necessário que as discussões sobre o que e quem os museus representam (os stakeholders) e para quem existem (cada vez mais turistas globalizados) em relação ao "fim" e sobre o "fim" adquiram destaque. Afinal de contas, já faz um tempo as agências turísticas especializadas organizam viagens nos arredores de Tchernobyl, com todos os confortos oferecidos e um contador geyger incluído no pacote...

\section{Referências}

ASSMANN, Aleida. Espaços da recordação: formas e transformações da memória cultural. Campinas; Unicamp, 2011.

AUGÉ, Marc. Rovine e macerie: il senso del tempo. Torino; Bollati Boringhieri, 2003.

AUGÉ, Marc. Disneyland e altri nonluoghi. Torino; Bollati Boringhieri, 2009

AUGÉ, Marc. Não lugares: introdução a uma antropologia da supermodernidade. Campinas; Papirus, 2010.

BENJAMIN, Walter. L'opera d'arte all'epoca della sua riproducibilità tecnica. Torino; Einaudi, 1987.

DAVIS, Mike. Cidades mortas. Rio de Janeiro; Record, 2007.

DIDI- HUBERMAN, Georges. "Costruire la durata". In: FERRARI, Federico. Del contemporâneo: saggi su arte e tempo. Milão; Bruno Mondadori Editore, 2007, pp. 21-52.

DIDI- HUBERMAN, Georges. A imagem sobrevivente: história da arte e tempo dos fantasmas segundo Aby Warburg. Rio de Janeiro; Contraponto/MAR, 2013

JEUDY, Henri-Pierre. Espelhos das cidades. Rio de Janeiro; Casa da Palavra, 2005.

MICHAUD, Philippe-Alain. Aby Warburg et l'imege en mouvement. Paris; Macula, 1998.

SILVA, Armando. Imaginários: estranhamentos urbanos. São Paulo; SESC, 2014.

SONTAG, Susan. Sobre fotografia. São Paulo; Companhia das Letras, 2004.

VERCELLONI, Virgilio. Cronologia del museo. Milão; Jaca Books, 2007.

ZEVI, Adachiara. Monumenti per difetto: dalle fosse ardeatine alle pietre dell'inciampo. Virgola, n. 107, 2014 